\title{
ARTICLE
}

\section{The Borders of Engineers Without Borders: A Self-Assessment of Ingenieros Sin Fronteras Colombia}

\author{
Andrés F. Valderrama Pineda, ${ }^{*}$ Richard Arias-Hernández, ${ }^{\dagger}$ María C. Ramírez, ${ }^{\ddagger}$ Astrid Bejarano, ${ }^{* *}$ and \\ Juan C. Silva ${ }^{*+}$ \\ * Technical University of Denmark, afvp@dtu.dk \\ † Simon Fraser University, ariasher@sfu.ca \\ ‡ Universidad de los Andes, mariaram@uniandes.edu.co \\ ** Universidad de los Andes, dabejarano1@misena.edu.co \\ *+ Universidad de los Andes, jc.silva121@uniandes.edu.co
}

This article results from a process of self-assessment within Ingenieros Sin Fronteras Colombia (ISFC). The activities usually referred to as humanitarian engineering, assistive engineering, engineering for aid, and/or engineering for development are increasingly involving educational frameworks, activities, and institutions in service-learning schemes. In this article, we discuss the issues and challenges that arise from this combination of objectives, activities, and institutional settings, especially when these approaches are implemented in the Global South. To do so we reflect on the type of service learning we are conducting in Colombia. We develop a general service learning in engineering typology to situate our work. We find that our Local Learning in the South collaboration makes the work of ISFC both different than and similar to other service-learning engagements. It is different in the sense that local engagements do not experience the cultural and language barriers faced by cross-cultural projects. It is similar in the sense that, with the exception of the cross-cultural challenges, our projects run the same risks as any other service learning in engineering projects in the world. To reflect on these risks we propose a set of five questions to self-assess our work. Thinking about the choice of naming our work "ingeniería sin fronteras" (engineering without borders), we consider what kind of borders we are dealing with and propose five: financial, epistemic, engineering educational, knowledge, and reputation. We invite other organizations to question the kind of borders their work aims at eliminating but risks replicating.

KEYWORDS: self-assessment, service learning, Engineers Without Borders

\section{INTRODUCTION}

As we celebrate the increasing popularity and institutional growth of Ingenieros Sin Fronteras Colombia (Engineers Without Borders Colombia), we have also become aware of the need to critically reflect upon our organization's goals, orientations, and activities. Like many other scholars, activists, engineering students, and faculty members around the world, we also believe in the need for self-assessment. Fortunately, many organizations not only do this internally but also share their insights, turning them into relevant, validated, and shared knowledge that we can discuss and to which we can contribute. This is the principal objective of this paper: to contribute to the reflective discussion of the activities of organizations like Ingenieros Sin Fronteras Colombia (ISFC). All of the authors of this paper have been involved directly with the activities of ISFC. Valderrama was one of the founding members of ISFC during its first phase in 2005-2006. Ramírez 
and Arias took the lead of ISFC during its second phase in 2007, and since 2008 Ramírez has had the leading role of ISFC. Bejarano and Silva are members of ISFC and have participated as students, coordinators, and associate researchers.

Through our analysis of the development of Ingenieros Sin Fronteras Colombia (ISFC), we undertake the task of re-thinking the foundational principles and the guiding questions of these types of organizations around the world. What are the main objectives of such organizations? Are they legitimate objectives? What are the frontiers or borders that such organizations aim to eliminate? Are there any borders that should be maintained, reestablished, or established anew? Who wins and who loses from the activities of ISFC and its many partner organizations around the globe? The analysis of the Colombian case shows that the activities of Engineers Without Borders (EWB) and similar organizations have become part of the educational content of engineering schools in recent years. Schools include these activities under service-learning frameworks referring to them as humanitarian engineering, assistive engineering, engineering for aid, and/or engineering for development. In this article, we discuss the issues and challenges that arise from this combination of activities and institutional settings, especially when these approaches are implemented in the Global South.

The analysis of the Colombian case shows that the service learning form of EWBs tends to reproduce borders in spite of their goal to deconstruct them. For example, projects that focus on products or artifacts are more commonly found than those that focus on process and capacity building; projects in rural areas are preferred by faculty to projects in urban areas; the metrics of service learning overshadow the measurable impact in the target communities (which is related to the fact that projects in which available knowledge can be applied are preferred by faculty to projects where new knowledge needs to be developed). In addition, this is all directed by faculty members whose engagement with such activities is tolerated but not fully endorsed by engineering schools that consider these types of activity as less than "real engineering research and development."

This article is organized in five sections. First, we present a short history of ISFC. Second, we propose a framework of analysis through an examination of the name the organization decided to adopt: engineers without borders. In the third section, we present a discussion of what we consider to be the most important tension in our work, namely between education of students and cooperation with communities. In the fourth section, we apply the framework elaborated in the previous section to our own activities in Colombia. And in the final section, we draw some conclusions and suggest future lines of research.

We ask the reader to understand that we want to contribute to an ongoing reflective dialogue with a point of departure in our own self-assessment. We would like to invite members of similar organizations to receive our thoughts also with a reflective attitude. We claim that not all the activities that we perform under such well-intended labels as humanitarian engineering, assistive engineering, engineering for aid, and/or engineering for development succeed in achieving the goals they express. In many cases, these activities may be of more value to the intervening students and activists than to the communities that should be the real beneficiaries of the effort (Heron, 2007). We propose that only an honest and analytically grounded study of our own actions can contribute to refining our goals, our means, and our projects in order to avoid the betrayal of our own intentions-namely, to avoid replicating a neo-colonial attitude (Schneider et al., 2009). 


\section{INGENIEROS SIN FRONTERAS COLOMBIA (ISFC)}

ISFC started in 2005 when faculty members and students from two different universities began devising ways to develop projects in which engineering could effectively be used for the development of the most vulnerable communities in our own country. ${ }^{1}$ One of the institutions was Universidad de los Andes in Bogotá (hereafter Uniandes), which is an elite university founded and run by economically-privileged Colombians, most of whom have received part of their academic education and developed their careers at prestigious universities, mainly in the United States and Europe. (For a detailed history of the origins of Uniandes, see Valderrama et al., 2009.) The other institution was Corporación Universitaria Minuto de Dios (hereafter Uniminuto). Uniminuto is an institution for higher education that spun off the activities of one of the most successful conglomerates of Catholic NGOs in the country, Grupo Minuto de Dios. This conglomerate comprises various organizations that through decades of hard work have contributed to the welfare of many disadvantaged social groups in the country by providing them with food, housing, micro-credit, assistance following disasters, and community development (Arias-Hernández, 2008; Jaramillo, 2004; Trujillo et al., 2003).

Uniandes has been a strong knowledge think-tank for the country as a whole, while Uniminuto has been strong in providing education for students with limited economic means and supporting the activities of Grupo Minuto de Dios. Since 2003, the two universities have joined forces to complement each other and carry out joint activities. The former president of Uniminuto and many of the engineering faculty members were trained (and some even worked previously) at Uniandes, which facilitates the realization of concrete projects and plans in addition to formal agreements. Through the years, ISFC has become an important collaborative nexus for the two institutions, providing the opportunity for students and faculty members at Uniandes to profit from Uniminuto's experience working with communities in order to improve their living conditions.

The first community approached by ISFC was Barrio Ramírez, which is an urban settlement just two kilometres away from Uniandes, in downtown Bogotá. The Barrio Ramírez is a non-legalized settlement, where the majority of the inhabitants live on untitled pieces of land. Legally, they are in limbo because they bought land but were not given legal property rights. For this reason, the city has left them without water, electricity, and sewage. At the beginning of our collaboration, the community expressed the need for a common multi-purpose building. Before beginning any type of technical intervention, ISFC and the community leaders developed a thorough analysis of the diverse problems that the community faced. After this process, we all agreed to prioritize unemployment as the most important problem in the community. To solve, or rather to dissolve, this problem, ISFC and the leaders of Barrio Ramírez initiated a start-up company to recycle plastic, drawing on the vast experience of many of the inhabitants who had collected recyclable materials in the city for many years. This first experience can be considered a success, since the recycling plant is currently working and the community continues to autonomously operate the plant. The ability of the community to operate the plant without further intervention is a key success indicator of the solution. Former students who have moved on to professional jobs or to graduate studies overseas now support and continue to develop the project. However, there are no longer educational activities linked to Uniandes. It is a positive output that the project in Ramírez has a life of its own now, and it does not depend on student activities for further development.

\footnotetext{
${ }^{1}$ The emphasis here relates to the fact that the majority of organizations under the banner Engineers Without Borders gear their work to interventions in communities outside their own countries.
} 
During 2007 and 2008, members of ISFC began another project in Guayabal de Síquima, a rural settlement 150 kilometres from Bogotá. This community, like many others in rural Colombia, has access to relatively clean water that pours out naturally up in the eastern branch of the Andes Mountains in Colombia. However, analysis performed by ISFC members revealed the presence of Total Coliforms and E. Coli (Ramírez et al., 2010). Following a participatory-action research (PAR) methodology (McIntyre, 2008), ISFC members and community leaders found that the best solution involved purification of the water by improving the infrastructure and installing water filters in every home. During the project's implementation, 14 filters were installed with the help of the community. After the project's completion, the community members further assembled and installed two more filters on their own, with relatively little technical assistance from the group of engineers. The project, which was developed in collaboration with faculty members and students from the University of Nankai in China, received the Mondialogo Engineering Award (MEA) in 2009. The winner of a contest sponsored by UNESCO and Daimler, the MEA recognizes engineering projects aimed at achieving the UN's Millennium Development Goals. Faculty members and students involved in the project documented their experience and, in collaboration with members of Engineering Without Borders Milan, developed new knowledge regarding collaboration with rural communities for the implementation of engineering projects (Ramírez et al., 2010b).

Since 2009, thanks to the results obtained by ISFC and the alliances established with other groups and institutions, ISFC has undergone a phase of rapid growth. Currently, the group is implementing several projects and several others are under study for future implementation.

\section{Current Projects}

- Bogotá Agua: During the first half of 2010, students and teachers from different engineering disciplines participated in the Eco-Challenge category of the Talent and Innovation Competition (TIC) - Americas, sponsored by the Young Americas Business Trust (YABT) and Pepsico. The group's proposal, aQua Soluciones, which sought to provide safe water in emergency situations, was chosen as best community solution. The project is currently under implementation in the Mochuelo community in Ciudad Bolivar and has allowed the team to develop improved water filtering technology.

- China: Work with Nankai University is still underway within the frame of the proposal presented at the MEA competition to design a sustainable, cost effective water filtering solution that responds to the particular problems and characteristics of a rural community in the Wuqing district.

- Phase 2 Cundinamarca: The group is currently working on the implementation of individual filters in the San Felipe district. This project is a continuation of the project proposal presented at the MEA competition in 2009.

- Tolima: ISFC is currently elaborating a cooperation agreement with the Universidad de Ibagué to work with the Icononzo district towards the improvement of water quality in the region through engineering solutions that are culturally appropriate and financially sustainable.

\section{Future Projects}

- EWB Milano: The project's aim is to identify opportunities for local sustainable development in accordance with the Millennium Development Goals set by the UN. The group is identifying and analyzing suitable candidate communities. 
Most of the projects being developed or evaluated by ISFC are multidisciplinary in nature, since they actively involve the community in the identification of problems and the design of viable solutions, and often involve several local and international institutions in an effort to approach these problems from multiple perspectives. ISFC's aim is to have an impact in different regions across the country, which is why the organization has worked hard to establish alliances with universities throughout Colombia with which and from which learning can be achieved through the design and implementation of engineering projects. For example, ISFC involves in its activities students from the social work program at Uniminuto.

\section{EXAMINING BORDERS: A TENTATIVE FRAMEWORK}

Since the annual meeting of ISFC in 2009, some members of the organization have been considering the need to develop a framework to assess the degree of success of its activities. Awareness exists of the risks involved in developing engineering projects with communities, as Uniminuto's experiences have widely shown. These preoccupations are also widely shared among activists and analysts in relation to development and humanitarian activities (Escobar, 1995). The risks associated are related not only to the conditions of the community, but also to the quality of the cooperation between the engineers and the community, the methodologies used, and also the way in which the story of the project is rationalized during and after the project (Nieusma \& Riley, 2010).

In addition to local experience, ISFC started exchanges with other similar organizations around the world. Members of ISFC were present at the annual meeting of Engineers Without Borders USA in Denver, Colorado, USA in September 2004. ISFC was also represented in a first attempt to organize EWB-International with a meeting in Paris in May 2005 at UNESCO. At both events, members of different organizations expressed their concerns about the risks involved in inviting faculty members and students from rich universities in the Global North to perform short-term interventions in communities of the Global South. The main concern expressed at those meetings was related to the production of project implementation opportunities for engineering students and faculty to obtain knowledge, prestige, and travelling opportunities at the expense of the communities' long-term needs.

Throughout the years, members of ISFC have experienced active exchange and discussion with members of Ingeniería Sin Fronteras in Spain, Ingegneria Senza Frontiere in Italy, and, more recently, Ingeniører Uden Grænser in Denmark. These organizations have taken actions to confront the risks referred to above. The organizations in Spain and Italy have reduced the number of locations where they intervene, and they have made sure that projects with different communities span over longer periods of time. The organization in Denmark has developed expertise in training professional engineers in "international disaster-relief experience who can rapidly respond to emergencies worldwide” (EWB-DK, 2010).

ISFC's relationships to other similar organizations in the world highlight the need to develop a conceptual framework to organize reflections on the type of work we do. In this paper, we start by examining the names these organizations have chosen to present themselves to the public. This approach makes sense for two reasons: first, because names are produced during the initial stages of the constitution of an organization, where the founding members consciously discuss and select a name that reflects their objectives; and second, because names have agency. They convey meanings and ideas (and prejudices), sometimes exceeding or betraying the objectives of the members of 
such organizations. This happens because names have a long history and genealogy that predates the use given by any specific new organization.

There are four elements in the name chosen by our organization: Ingenieros, Sin, Fronteras, and Colombia. The first element, which means "male engineers," is already problematic, as our partners in Spain and Italy have noted. They have chosen instead ingeniería and ingegneria, which mean "engineering," to emphasize that the organization comprises not only individual (male) professionals from a discipline but anybody who is concerned with this discipline. Sin means "without." And Fronteras means "borders". This combination conveys the idea that there are some existing borders that the members of this organization are committed to eliminate, or even more arrogantly, that members of this organization have the privilege of being unbounded by borders that may constrain some other people (e.g. the asymmetric privileges of United States citizens to travel to most other nations versus the cumbersome process of citizens from targeted nations to travel to the United States). Finally there is the term Colombia, which indicates that membership in the organization is confined to citizens of a specific country, like any other organization with a similar name. EWB-International is no exception, since it is an association of established national organizations.

From this preliminary name analysis, then, follows the questions: What are the borders we want to eliminate? What are the borders that our social privileges allow us to ignore? Are we interested in eliminating geo-political borders? Or is it economic borders? Or is it social borders? Why not consider also racial and gender borders? And is it useful to think of "engineering" borders in this way?

It is quite telling that the majority of EWBs in the Global North only develop projects with communities in the Global South (with the exception of ISF Italy and EWB Australia, to our knowledge). Does not this way of constituting the organization replicate the asymmetries and thus the borders of the discourse of development? According to Arturo Escobar (1995), the discourse on development replaces the colonial notions of progress and the natural domination of superior races over inferior races with an ideal of different stages of development-advancement can be achieved by any nation mainly through science and technology. If we accept that some nations are already ahead (they have the technical knowledge), then we assume they have the moral imperative to help those lagging behind (those which do not have the knowledge but need it the most). And are engineers from developed nations not the most qualified to do the job? The problems with this rationale have been exposed by Escobar's work and also other historical and contemporary studies, which reveal that engineering has had a decisive role in creating the geopolitical borders that exist today, along with the economic dependencies and social differences (Adas, 2006; Baillie, 2006; Headrick, 2009). Therefore, the question that emerges from these considerations is whether or not the activities of EWBs (or any other "development" organization) may risk contributing to contemporary social problems rather than solving them.

We are aware that organizations like ISFC do not escape these risks. Although we do not develop projects outside the country, faculty members and students at our universities are relatively well off in our country, and they work at institutions that develop and concentrate expert technical knowledge. Approaching communities, especially in poor urban areas and in rural areas, can produce situations where the discourse on development is replicated. In other words, we might be creating asymmetric situations where one group of people has expert technical knowledge in advance of another group of people without such specialized knowledge but with an unsolved need (which the first group does not suffer), and where a relationship of "help" is enacted (Schneider et al., 2009). 
There are various strategies to further understand and illustrate the type of risks ISFC and similar organizations face. Some provoking thoughts can be illustrated by the following questions:

1. Do we not contribute to the existence of a financial border when the contribution of only one side-the engineers and engineering students-is taken into account, often because it includes support from a private organization or company?

2. Do we not contribute to creating an epistemic border when students and researchers privilege engineers' perspectives over disempowered groups' perspectives in order to use their experience with the communities to develop further their engineering knowledge?

3. Is there not a demarcation effort to sustain an engineering education border when academic administrators label these types of experiences as a diversion from "real" engineering training for teachers and students?

4. Do we not continually re-enact a knowledge border when the technical knowledge deployed is considered scientific and the knowledge gathered during the process is considered nonscientific, sub-scientific, or "social"?

5. Do we not contribute to creating a reputational border when it is only the engineers who board the airplane to receive international awards, while the community members remain absent?

These five questions indicate the tensions that members of organizations like ISFC have to face. Are we using communities as an experiential source for training engineers? And are we replicating development paradigms in our interventions in communities? The ideal, of course, would be that we structure service learning in a way to avoid the replication of development paradigms. But are we sure it is working for all of the parties involved? As a provoking thought, one member of ISFC proposed the following question: If the students and faculty members are the ones who learn most from the experience (Heron, 2007), should they not pay the communities for their educational services?

To contribute to the development of an analytical framework that can be used to help answer the above questions, we propose the following typology of service learning. This is a tentative exercise developed with the intention of provoking thought, reflection, and assessment of the work we do in our organization and the work done in similar organizations around the globe.

\section{SERVICE LEARNING IN ENGINEERING: A TYPOLOGY}

"Service learning" represents a broad category of educational initiatives oriented toward providing academically informed solutions to serve the needs of the poorest and most marginalized while offering experience-based learning environments for students. "Service learning" in engineering education, specifically, locates the origin of these initiatives in engineering colleges or universities and focuses on engineering knowledge, technologies, students/teachers, and practices. Service learning differs from related approaches such as community-based learning (CBL) (Mooney \& Edwards, 2001) and participatory action research (PAR) (McIntyre, 2008). Both CBL and PAR are characterized for acknowledging more explicitly the power structures that mediate between the members of the involved social groups. Service learning in engineering is still far from developing a structured social critique of its interventions. Also both, CBL and PAR recognize the relevance of distributing more symmetrically the process and benefits of learning between all the social groups involved, something that service learning in engineering still struggles with. Finally, both CBL and PAR incorporate critical reflection and participation as integral parts of the methodology, 
something that it is commonly ignored in service learning in engineering. In the following, we use "Service learning" to refer to service learning as it is currently practised in engineering schools.

Service learning has been mostly used in literature written by North American engineering scholars to characterize these educational initiatives within the context of North-South relations of "development". In other words, a political and economic distinction that separates developed from developing countries (Global North vs. Global South) normally structures service learning initiatives. Engineering schools from the Global North provide expert technical knowledge and students, while poor communities from the Global South provide the experiential learning environment where problems are to be found and solved. For example, Johnson (2009) describes a service learning project in which engineering students from an American university installed a wind turbine in a remote community on an island in Nicaragua. The locals provided the problem to be addressed by design: "generating enough energy to power lights in a small health clinic and a classroom for adult education classes and for an emergency radio to call for an ambulance from the nearest hospital on the island" (Johnson, 2009: 18). The American students provided the engineering knowledge, design process, and technology to solve this problem.

Other scholars have noted that service learning in engineering is structured according to the "expert-model" proper of development projects (Riley, 2006). For example, Nieusma and Riley (2010) characterize "service learning" as a sub-category of "engineering-for-development" programmes in USA and Canada. In their conceptualization, American and Canadian universities have followed two approaches for engaging in "engineering-for-development." The first approach is used when universities sponsor development projects abroad that do not involve the participation of students. The second approach is used when engineering schools develop courses or entire academic programmes to service communities in developing countries. This second approach is the one that corresponds to "service learning." In both cases, it is the development mentality that structures and provides the moral justification for engineers from the Global North helping poor communities in the Global South (Schneider et al., 2009).

This theorizing of service learning is relevant and very useful for highlighting its neo-colonial and neo-liberal implications (Schneider et al., 2009). However, overemphasizing service learning projects that mirror development projects has also served to obscure the existence of other approaches to service learning-namely, local experiences of service learning both in the South and in the North (Dukhan et al., 2007; Mehta et al., 2007; Duffy et al., 2008). Moreover, within this framing of service learning, it is difficult to envision-or capture if they exist, creative initiatives that switch traditional development roles. To remedy this, we propose four scenarios organized by roles and spatial location in order to widen the theoretical net for capturing service learning initiatives and for situating the current activities of ISFC. We understand the risks of oversimplification, but at the same time we want to propose this classification as a tool to think and reflect. (See Table 1.)

\begin{tabular}{|l|l|l|l|}
\hline \multicolumn{2}{|c|}{} & \multicolumn{2}{c|}{ Targeted Communities } \\
\cline { 3 - 4 } & \multicolumn{2}{c|}{ South } \\
\hline \multirow{2}{|c|}{} & $\begin{array}{l}\text { a. LSL: Local service learning (North) } \\
\text { b. OSLN: Overseas service learning in the } \\
\text { Global North (North-to-North) }\end{array}$ & $\begin{array}{l}\text { SL4D: Service Learning for } \\
\text { Development (North-to-South) }\end{array}$ \\
\cline { 2 - 4 } & $\begin{array}{l}\text { SL4AD: Service Learning for Alternative } \\
\text { Development (South-to-North) }\end{array}$ & $\begin{array}{l}\text { a. LSL: Local service learning (South) } \\
\text { b. OSLS: Overseas service learning in } \\
\text { the Global South (South-to-South) }\end{array}$ \\
\hline
\end{tabular}

Table 1. Scenarios by role and spatial location for capturing service learning initiatives 
The bulk of the literature and critique of service learning is centred in SL4D (Service Learning for Development) as we already mentioned. However, even within a developmental paradigm, we can observe that other configurations of actors and places exist for structuring service learning. For example, several cases of LSL (Local Service Learning) experiences have been documented in North America (LSL-North) (Dukhan et al., 2007; Mehta et al., 2007; Duffy et al., 2008). These experiences contrast with SL4D (Service Learning for Development) in that LSL locates the focal points of experiential learning and the problems to be addressed by engineering students not overseas but in their own local communities, generally not too far from where the educational institution is located. Some advantages of this approach to SL4D are: reduced travel costs, more cultural affinity, fewer language barriers, better knowledge of socio-economic realities, more accountability from educational institutions, and increased probabilities for long-term alliances and commitments between engineering schools and communities. Some of these advantages even translate to Overseas Service Learning to proximal countries, wherein much common cultural ground already exists. Consider, for example, OSLN (Overseas Service Learning in the Global North) projects between Canada and the United States, or OSLS (Overseas Service Learning in the Global South) projects between Colombia and Ecuador. Finding documentation of LSL in the South and OSLS experiences is challenging since most of these do not get published in mainstream American or European journals. This paper attempts to motivate service learning practitioners to change this situation. In Colombia, most of ISFC projects, for example, directly engage with LSL (South) and ISFC just started an OSLS project with China, which we elaborate further below.

It is important to note that even local experiences, such as LSL (South), can still be connected to the development paradigm because of social differences between those who serve and those who are served, for example, when wealthy students from a rich, private university approach neighbouring poor urban or rural communities. However, despite this concern, their shared local knowledge and culture permits the emergence of varied and creative forms of service learning.

The last form of service learning presented in this typology is still very invisible and would present a radical challenge to dominant structures of development. SL4AD (Service Learning for Alternative Development) conceptualizes service learning initiatives that originate in engineering schools in the South in order to improve conditions in communities in the North. However, due to its marginalized position with respect to the dominant structure of development, these kinds of initiatives face several kinds of hurdles: from financial hurdles to deeply embedded prejudices in the North regarding engineers and engineering from poor countries attempting to solve their problems.

\section{ISFC: SELF-ASSESSMENT}

Our organization's case belongs to the LSL (South) quadrant in the typology shown above. From the list of current projects being developed, it is obvious that most projects are local. Our aim is to develop projects with communities in local environments close to the institutions where our members work and study. This greatly facilitates long-term contact and avoids situations where language barriers can become a big issue. Currently, one on-going project that ISFC is developing involves using knowledge derived from local experiences in Colombia to develop projects in similar contexts in rural communities in the Wuqing District, Tianjin, China. If successful, this experience will demonstrate the feasibility of ISFC expanding from LSL to OSLS (South-to-South) experiences. At present, this project is at a very early stage; we expect to document further developments in future papers. 
Given the history of ISFC and the current state of the organization and the projects, what can we say about the five questions about the borders of engineering without borders? Let us turn a critical eye to our own work, as an invitation to other organizations around the world to carry out a similar exercise with regard to their own organizations. To focus on one specific activity, we only assess our work in Guayabal de Síquima, since this is our best-documented project so far (Ramírez et al., 2010a, Ramírez et al., 2010b).

1. Do we not contribute to the existence of a financial border when the contribution of only one sidethe engineers and the engineering students-is taken into account, often because it includes support from a private organization or company?

The Guayabal de Síquima project costs amounted to approximately US\$14,000. Roughly half of that figure was spent for the fabrication of filters and preparing the water infrastructure of the community. The other half was spent on transportation, laboratory analyses, and project management. ISFC members were able to mobilize most of the resources from their regular university activities. Uniandes thus contributed roughly US\$ 8,500 from different research and administrative support funds, while Uniminuto contributed US\$ 4,500. The community contributed US\$ 1,000 in materials, but it also contributed all the labor to design, test, and construct the filters. It is difficult to quantify and compare the labor contribution, so it is not counted in the financial total. As a result, their contribution disappears from the accounting of the project. Unaccounted costs were paid directly by ISFC members and the community as voluntary contributions. ISFC members were able to mobilize resources from their institutions, since they succeeded in aligning the project with regular education and research activities. However, this institutional reality clearly demands that the group members are very precise in accounting for the universities' contributions, while the communities' contributions are downplayed. In the future we are aware that something has to be corrected in order to value all contributions in a fashion that reflects better the efforts of all the parties involved.

2. Do we not contribute to creating an epistemic border when students and researchers privilege engineers' perspectives in order to use the experience to develop engineering knowledge?

In response to this question, we must admit that, based on the work in Guayabal de Síquima, members of ISFC produced a number of written and visual documents in Spanish and English, which were directed to academic partners around the world, including the students and faculty of the University of Nankai and participants at several international academic meetings. In addition, the project was presented at the Mondialogo Engineering Award ceremony, where it won a prize. Therefore, it is clear that students and faculty have profited in their own careers from the work carried out with the community. The question is whether this was done at the expense of the community. Community members were involved in the process of design, test, and construction of the filters. Therefore they contributed to the elaboration of the documents as interviewees and sources of valuable knowledge. It is true that they did not participate in the writing of the documents as authors. Nonetheless, these documents served as basis for the application of new funding. This has made possible a second phase of development in this same community.

3. Is there not a demarcation effort to sustain an engineering educational border when academic administrators label these types of experiences as a diversion from "real" engineering training for teachers and students?

ISFC activities have been both supported and criticized at both Uniminuto and Uniandes. On one hand, several faculty members, administrative employees, and academic leaders, including the 
rectors of both institutions, have explicitly supported the activities of ISFC. In Uniandes, ISFC has become a valid space for developing mid-career projects as part of the curriculum of all the programs of the Engineering School and undergraduate and master's theses. Teachers and students have formalized the lessons from the projects in two types of academic journals: those concerned with local development projects; and those concerned with organizations and strategy. However, many colleagues at the engineering schools have expressed doubts that these activities are "real engineering" at the same technical level of other established research and practical engineering activities. More recently, however, ISFC's activities have become quite relevant at Uniandes due to external pressure. The engineering school obtained ABET accreditation, and ISFC's activities fulfill the requirements of social engagement demanded by the accreditation criteria.

4. Do we not continually re-enact a knowledge border when the technical knowledge deployed is considered scientific and the knowledge gathered during the process is considered non-scientific, subscientific, or "social"?

Aware of the necessity to understand the social impact of the projects, social work teachers and students from Uniminuto have been involved alongside engineering teachers and students. The discussions and interdisciplinary proposals resulting from cooperation among the community, engineers, and social workers have generated an evolution in the projects that is reflected, for example, in improvements in interactions with local stakeholders and self-evaluation of projects' social impacts. This experience supports the reflections and experiences of our partners in Spain and Italy, who have recommended that we change our name to Ingeniería Sin Fronteras Colombia (Engineering Without Borders Colombia). The change from naming the professional (male) social group, Ingenieros (male engineers), to emphasizing the discipline, Ingeniería (engineering), provides the opportunity to be fairer to reality. It is accepted that engineering companies and firms hire all sorts of professionals for their work, so our organization should also reflect this in its name. However, it is also sadly true that names acquire momentum and their material existence in contracts, agreements, and other formal documentation can hinder or delay taking this step.

5. Do we not contribute to create a reputation border when it is only the engineers who board the airplane to receive international awards, while the community members remain absent?

It is true that it was the students and faculty members who attended international events to present the results of this project, to receive the prizes, and to publish the papers. However, none of these activities and processes was supported by project funds. All these activities were supported by ISFC faculty members' research funds, by students' families who supported their trips, and by Uniandes' internal funds to support faculty members' travel to academic congresses. Moreover, the national and international visibility achieved through these activities has made possible the mobilization of resources for development of the second phase of the project in Guayabal de Síquima and other ISFC projects. It can be argued that the project's implementation is distinct from the process of creating knowledge from that implementation. Nevertheless, it is also true that none of the community members was included as an author of the documents; they did not count as creators of knowledge. And looking to the future, we might be rethinking this strategy. Should not some of the members of the community also be authors of the papers that formalize the knowledge developed through the implementation of the project? However, it is also true that their authorship would not be rewarded as it usually is for academics in their careers. A more practical learning objective is to support the community so that they can autonomously apply for the many local, regional, and national funds that support local development projects. 


\section{CONCLUSIONS}

We believe our reflective exercise is pertinent to all organizations that develop projects referred to as humanitarian engineering, assistive engineering, engineering for aid, and/or engineering for development. They all increasingly involve educational frameworks, activities, and institutions under a service learning framework. If groups carrying out engineering projects within this framework are to respond adequately to the challenges raised here, we argue it is essential that they develop, maintain, and enrich a reflexive attitude to their work, to their methodology, and to their approach altogether. In this paper we have documented our own reflections in order to develop an assessment framework, which we hope will be generally valid. We leave it to other organizations to take up this proposal, use it, criticize it, and hopefully improve it. The ultimate aim is for all organizations involved in any type of work related to engineering, social justice, and peace to develop ways of assessing whether they are doing things right, minimizing risks, and, most importantly, making sure that they truly work together with communities to put the communities' interests above their own.

Based on our proposed matrix characterizing the work of similar organizations, we argue that the current North/South divide poses a major challenge to the type of work we all do. Perhaps this is the biggest border to overcome, but to consider such a move requires first recognizing that the border exists, and that our work might be helping to sustain the divide rather than destroying it. The very fact that Service Learning for Development (SL4D) appears to be a natural response to inequality is evidence of the centrality of this border: For many organizations it is obvious that they can and should use the capacity of young, motivated students from rich universities in the North to solve the problems of poor communities in the South. But the opposite seems to be incongruous. Service Learning for Alternative Development (SL4AD), where engineering students from the South go to the North to solve their problems, is not only uncommon but is interpreted as verging on the illogical. The North/South divide is only a semi-permeable border in our minds, which has physical and normative manifestations. But the conceptual divide is of our making. To overcome it, the first step is to understand where and how our work challenges this divide and where and how we inadvertently reproduce it.

We have turned a critical eye on the name of our organization, Ingenieros Sin Fronteras Colombia (Engineers Without Borders Colombia), to explore the strengths and weaknesses of our approach. This exploration was motivated by a number of questions relating to existing borders, to the ideal of a "borderless" world, and to our own specific practices. We put forward five questions, each around a different type of border, and answered the questions as a means of exploring our work practices. We believe that organizations with names or missions similar to ours would also benefit by answering, or further developing, these questions for themselves. By interrogating the borders of "engineers without borders," and by critically assessing our own practices and assumptions, we hope to provide a model of reflective analysis applicable to many who work in the name of engineering, social justice, and peace.

\section{ACKNOWLEDGEMENTS}

This article was made possible by support from the Technical University of Denmark in Denmark and Universidad de los Andes in Colombia. We would like to thank the editorial team and the journal's blind reviewers for helpful suggestions in response to a prior version of this paper. 


\section{REFERENCES}

Adas, M. (2006). Dominance by design: technological imperatives and America's civilizing mission. Harvard University Press.

Arias-Hernández, R. (2008). Engineering the network society: a social worlds/arenas analysis of engineering in government and non-governmental organizations in Colombia. Unpublished Dissertation, Science and Technology Studies, Rensselaer Polytechnic Institute, Troy, NY.

Baillie, C. (2006). Engineers within a local and global society. Morgan \& Claypool Publishers.

Colledge, T. (2006). Editorial, In: International Journal for Service Learning in Engineering, Vol 1, No 1.

Duffy, J., Barington, L., Moeller, W., Barry, C., Kazmer, D., West, C., and Crespo, V. (2008). "Service-learning Projects in Core Undergraduate Engineering Courses". International Journal for Service Learning in Engineering, Vol 3, No 2, pp. 18-41.

Dukhan, N., Schumack, M.R., Daniels, J.J., Jenkins, M.G. (2007). Service-learning Case Study in Heat Transfer. International Journal for Service Learning in Engineering, Vol 2, No 1, pp. 1-15.

Escobar, A. (1995). Encountering Development: The Making and Unmaking of the Third World. Princeton University Press.

EWB-DK (2010). Engineering Without Borders - Denmark: Rapid Response Unit. Retrieved from http://iug.dk/index.php/uk/iug-i-danmark. Consulted on: Oct. 10th, 2010.

Headrick, D. (2009). Power over peoples: technology, environments and western imperialism: 1400 to the present. Princeton University Press.

Heron, B. (2007). Desire for Development: The Education of White Women as Development Workers. Wilfrid Laurier Univ. Press.

Jaramillo, D. (2004). Rafael García Herreros: Una Vida y Una Obra. Corporación Centro Carismático Minuto de Dios, Bogotá, Colombia.

Johnson, P.E., (2009). Direct and Indirect Benefits of an International Service-learning Design Project: Educational Effects on Project Members and Their Peers. International Journal for Service Learning in Engineering, Vol 4, No 1, pp. 15-30.

McIntyre, A. (2008) Participatory Action Research. Qualitative Research Methods Series 52. Sage Publications, Inc: Thousand Oaks.

Mehta, Y. and Sukumaran, B. (2007). Integrating Service Learning in Engineering Clinics. International Journal for Service Learning in Engineering, Vol 2, No 1, pp. 32-43.

Mooney, L.A. and Edwards, B. (2001). Experiential Learning in Sociology: Service Learning and Other Community-Based Learning Initiatives. Teaching Sociology, Vol. 29, No. 2 (Apr., 2001), pp. 181-194. American Sociological Association.

Nieusma, D. and Riley, D. (2010). Designs on development: engineering, globalization, and social justice. Journal of Engineering Studies, Vol 2, No 1, pp. 29-59, Routledge.

Ramírez, M., Bejarano, A., Silva, J. and Villegas, J. (2010a). Engineers Without Borders Colombia: Engineering at the service of the community, EWB-UK National Research Conference.

Ramírez, M., Bengo, I., Mereu, R., Bejarano, A. and Silva, J. (2010b). Participative Methodology for Local Development: The Contribution of Engineers Without Borders from Italy and Colombia: Towards the Improvement of Water Quality in Vulnerable Communities. Systemic Practice and Action Research.

Riley, D., and Bloomgarden, A.H. (2006). Learning and Service in Engineering and Global Development. International Journal for Service Learning in Engineering, Vol 2, No 1, pp. 48-59.

Schneider, J., Lucena, J., and Leydens, J.A. (2009). Engineering to Help. IEEE Technology and Society Magazine, Vol. 28, No. 4, pp. 42-48.

Trujillo, D., Gutierrez, R., Ruiz, J. (2003). “Los desafíos para el Minuto de Dios," In: Revista Latinoamericana de Administración. Consejo Latinoamericano de Escuelas de Administracion, pp. 23-52. 